\title{
A Construção da Identidade Docente numa Prática Educacional Complexa
}

\author{
Antonia Karla de Oliveira ${ }^{I}$
}

Resumo: O presente artigo tem como tema A Construção da Identidade Docente numa Prática Educacional Complexa, tem como objetivo discutir obstáculos e complexidades que dificultam a construção da identidade profissional docente, com abordagens relacionadas ao processo de formação do professor e as interferências que complicam a composição da autonomia e autenticidade da imagem do professor. Como metodologia se optou por estudos pautados no campo da Formação e Identidade Docente, com embasamentos em leituras, pesquisas e discussões teóricas de obras, artigos, periódicos e legislações relacionadas ao tema. Para uma análise das discussões foi organizado um estudo bibliográfico nos autores: Mosé (2015), Campos (2011), Freire (2015), Perrenoud (2000), Lessard e Tardif (2008), dentre outros.

Palavras-Chave: Identidade Docente, Formação de Professores, Prática Educacional.

\section{The Construction of Teacher Identity in a Complex Educational Practice}

\begin{abstract}
The purpose of this article is to Construct the Teaching Identity in a Complex Educational Practice, whose objective is to discuss obstacles and complexities that make difficult the construction of the professional identity of teachers, with approaches related to the teacher training process and the interferences that complicate the composition of the autonomy and authenticity of the image of the teacher. As a methodology, studies were chosen based on the field of Teacher Training and Identity, based on reading, research and theoretical discussions of works, articles, periodicals and related legislation. For an analysis of the discussions a bibliographic study was organized in the authors: Mosé (2015), Campos (2011), Freire (2015), Perrenoud (2000), Lessard and Tardif (2008), among others.
\end{abstract}

Keywords: Teaching Identity, Teacher Training, Educational Practice.

\section{Introdução}

Falar do exercício da carreira docente na atualidade é indagar os diversos motivos pelos quais esta profissão vem se tornando cada vez mais árdua e pouco atrativa na sociedade.

A prática docente não pode ser percebida apenas no âmbito da intelectualidade, a pluralidade de funções que são impostas às escolas públicas, direciona a trajetória profissional a um contexto inserido em valores e atitudes que se pautam nas relações sociais.

\footnotetext{
${ }^{1}$ OLIVEIRA, Antonia Karla de. Historiadora, Especialista em História do Brasil e Gestão Escolar. Mestranda em Educação Anne Sullivan University.
} 
A dinâmica da sala de aula está incorporada numa concepção de trabalho educacional marcado pela complexidade de ações, que necessitam ser desenvolvidas de acordo com a realidade social evidenciada pelas escolas públicas nos dias atuais, o que muitas vezes as distanciam da verdadeira função que é a promoção da aprendizagem.

Esta problemática associada a outras mais, vem complicando o processo de constituição de identidade profissional dos professores e, consequentemente influenciam de forma negativa na qualidade do ensino público brasileiro. Neste sentido, este artigo procura questionar até que ponto certos obstáculos da carreira do magistério interferem na construção da identidade docente?

Percebe-se que a composição de identidade docente ultrapassa a marca conclusiva da formação docente adquirida na vida acadêmica, pois é na complexidade do cotidiano escolar que o professor se vê coagido a adquirir posturas imediatistas que vão além dos saberes pedagógicos adquiridos na graduação.

Historicamente no Brasil a formação docente teve como base um modelo de práticas técnicas, fora da realidade dos educando e educadores, estas raízes ainda inspiram muitas dimensões do sistema de ensino através de padrões determinados e impostos pelos detentores do poder.

\section{A formação docente e suas disparidades com a profissão}

Discutir como a profissão docente passa a ser uma alternativa para muitos que querem obter apenas um nível superior é algo bastante questionável. Muitos docentes ingressam numa vida acadêmica não por opção, mas pela falta desta, e é nesta circunstancia que no curso de formação docente há muitos impasses em relação ao teor da qualidade necessária para o desenvolvimento das habilidades e competências a serem desenvolvidas em sala de aula.

A falta de alternativa no mercado de trabalho provoca muitas vezes o desprazer pelo exercício da função docente, uma problemática que o ensino público vem suportando nos dias atuais e que vem diminuindo a atratividade da carreira perante a sociedade. 
O ensino público brasileiro ainda se vê atrelado aos interesses do poder dominante, que pouco se interessa pela educação em termos de prioridade e ainda a utiliza como mecanismo de manipulação da sociedade. A formação docente passa a ser então, um meio para tal ação, como afirma Campos (2011) “A formação de professores, é uma área estratégica em que o governo vai agir assumindo o controle ideológico do debate e das mudanças a serem propostas e implementadas." (p. 36)

Neste sentido a formação docente se modela de acordo com a legislação proveniente das decisões do Estado, ou seja, de cima para baixo e assim, os professores se preparam para o exercício do magistério da forma que o governo e seus representantes idealizam, sem condizer com a realidade de vida do profissional e nem de seus futuros alunos.

Há um choque evidente entre o que se "aprende" na formação acadêmica e o que se vivencia na sala de aula, a complexidade de funções que são submetidas às escolas ultimamente, pouco condiz com o que se desenvolve nos trabalhos acadêmicos dos cursos de pedagogia e licenciatura para atuação na Educação Básica.

Campos (2011) assim caracteriza essas disparidades entre teoria e prática:

\begin{abstract}
A crítica aos modelos de formação docente deve-se aos currículos de caráter aplicacionista, que possuem ampla densidade teórica, ou seja, os currículos dos cursos de formação de professor são constituídos de uma carga horária amplamente teórica. Somente no final do curso é que se tem a parte prática com os estágios. Esses são tidos como coroamento do curso, quando encerrada a formação. Era como se o professor formado não precisasse mais estudar, atualizar-se, não precisasse de permanente formação. (CAMPOS, 2011. p. 72)
\end{abstract}

Com as evoluções da sociedade do conhecimento a escola pública pouco acompanhou as inovações necessárias para tornar-se um espaço atrativo para sua clientela, o que dificulta muito o trabalho do professor, como bem afirma Lessard e Tardif (2008) "Os docentes às vezes vivem mal essas evoluções e constatam, impotentes, que não são capazes de concorrer com a mídia cada vez mais invasora e eficaz, pelo seu poder de sedução”. (p. 258)

Esta é uma fragilidade que incomoda o trabalho do professor, sabendo ele que sua própria formação muitas vezes é omissa das inovações necessárias para que realize um trabalho atrativo, e que atenda aos anseios de aprendizagem das crianças e jovens da atualidade. 
As instituições de ensino, seja elas de formação docente ou de exercício da profissão, não dispõe de forma adequada recursos materiais e humanos que possibilitem ao professor um enquadramento digno na realidade das Tecnologias da Informação e do Conhecimento. E assim, nas exaustivas tentativas de fazer o possível e até mesmo o impossível, o professor procura desenvolver o que está ao seu alcance, estabelecendo uma relação docente-discente muitas vezes conflituosa, que só acrescenta a sua labuta mais probabilidades para a indisciplina e falta de interesse dos alunos.

Tornar a aula atrativa é uma missão que muitas vezes desgasta a função do professor, uma experiência que não é refletida o suficiente na vida acadêmica e que no decorrer da carreira provoca uma demasiada insatisfação profissional e identitária.

Nesta direção é visível a precariedade da prática docente ofertada pelos cursos de graduação, assim como, a necessidade de firmar na sua consciência a importância da formação continuada no ofício do magistério.

O sentido das práticas pedagógicas é diversificado e variam de acordo com a realidade social e com o tempo cronológico. As mudanças que surgem a cada geração interferem ativamente no ofício do professor e, para atuar no contexto do novo e do atualizado, é essencial a busca do aperfeiçoamento constante, que Perrenoud (2000) assim considera: "A formação contínua acompanha também as transformações identitárias”. (p. 158)

Este autor considera a formação docente como uma das dez competências para ensinar na contemporaneidade, destacando assim os cinco principais componentes desta competência:

- Saber explicitar suas próprias práticas; - Estabelecer seu próprio balanço de competências e seu programa pessoal de formação continuada; - Negociar um projeto de formação comum com os colegas (equipe, escola, rede); - Envolver as tarefas em escala de ordem de ensino ou do sistema educativo; - Acolher a formação dos colegas e participar dela. (PERRENOUD, 2000. p. 158)

É interessante que o professor estabeleça uma postura própria em relação à sua formação continuada, encarando a mesma como um caminho que deve ser trilhado constantemente e que não termina enquanto estiver no exercício da função. Tem que agir com perseverança, não se limitando somente às políticas ofertadas pelo poder governamental, ou seja, não esperar apenas as oportunidades advindas do Estado para aperfeiçoamentos, mas se atentar como profissional 
que busca sua autoformação. Esta para Perrenoud (2000) “deveria ser, antes de mais nada, uma prática voluntária no âmbito da autonomia profissional”. (p. 164)

Nos cursos de formação docente ainda se constata em alguns pontos um condicionamento de visão de mundo, com objetivos voltados para a manutenção de paradigmas culturas impostos e aceitos pela sociedade de forma manipuladora.

Sobre a questão do paradigma em si, Neves (2010) esclarece a sua importância em meio a sociedade como um todo:

Tem-se visto que o paradigma (ou modelo) é, portanto, não só necessário mas imprescindível para a construção do sujeito, da cultura e da civilização. Entretanto, esses paradigmas devem ser vistos como modelos apenas balizadores, essenciais à construção que o homem está realizando do real ou de si próprio, mas nunca tomados com a investidura de absolutos, cristalizados. (NEVES, 2010. p.55)

Mesmo diante desta situação, os paradigmas são necessários para a composição dos grupos sociais, como forma de contribuição na formação do ser humano como sujeito e em sociedade, mas a autora ainda ressalta que estes paradigmas são vítimas das mutações. Assim, o que se percebe nos dias atuais são as poucas correlações existentes entre as mudanças dos paradigmas culturais e a realidade educacional.

$\mathrm{Na}$ verdade a crise dos paradigmas está neste campo das mudanças, o que marca o distanciamento que há entre a sociedade e a escola pública brasileira, esta não está aberta aos processos de inovações da atualidade, seja pela falta de condições ou pela resistência da maioria dos profissionais da educação, que não se veem preparados diante das complexidades que ferem os paradigmas tradicionais que insistem em perpetuar na maioria das escolas.

Esse tradicionalismo associado ao pouco interesse das autoridades competentes de se investir em um preparo docente de qualidade, gera consequentemente a crise do ensino que a cada dia vem demonstrando a queda do rendimento escolar dos educandos. Estes em sua maioria entram e saem da vida acadêmica sem adquirir conhecimentos necessários para uma atuação satisfatória na carreira profissional.

A questão se torna mais preocupante quando dentre estes profissionais despreparados está a figura do professor, responsável pela educação escolar de todas as profíssões. Este é um 
Id on Line Revista Multidisciplinar e de Psicologia

Id on Line Multidisciplinary and Psycology Journal

agravante que repercute no contexto socioeconômico do país, pois se a educação é de baixa qualidade, só haverá obstáculos para o desenvolvimento.

A realidade dos cursos de formação docente dos dias atuais vivencia uma crise, que de acordo com Ristoff (2012, on line) "esta é hoje uma situação do Brasil que, no tocante à formação dos seus professores, enfrenta uma tríplice crise: uma crise de quantidade, uma de qualidade e outra sistêmica".

Em relação à crise da quantidade o autor menciona a formação nas disciplinas específicas da Educação Básica, onde algumas há muita demanda e poucos professores, como por exemplo, a disciplina de Física, cuja carência de profissionais para ministrar aulas é presente em todo o país.

Já a crise da qualidade está associada aos baixos rendimentos dos índices das avaliações externas, provenientes de vários fatores, que dentre os mais atenuantes está à formação de professores em instituições privadas, que na sua maioria denotam um quadro de baixa qualidade.

Por fim o autor se refere à terceira crise relacionando-a aos poucos investimentos na área da educação e as complexidades de funções atribuídas ao ofício docente, estes fatores vêm estabilizando a crise sistêmica, que se caracteriza pela diminuição da procura dos cursos de pedagogia e licenciatura, cujo motivo principal é a falta de atratividade da profissão professor, principalmente na Educação Básica.

Essa situação educacional brasileira necessita de estratégias urgentes da parte do Sistema Nacional de Ensino, para um comprometimento a princípio com a formação de professores com qualidade e também, apoios e incentivos à formação continuada, tendo sempre em vista o grau de complexidades vivenciadas pela sociedade contemporânea.

\section{Os Obstáculos Identitários Docentes}

A construção da identidade profissional docente é um processo intrapessoal que requer muitas atitudes individuais influenciáveis pelo meio e pelas condições de trabalho. 
Este processo se constrói desde a formação do professor, de forma inacabável, onde a postura e perseverança profissional são de suma relevância para a transformação identitária.

É importante ressaltar a relevância que a formação permanente tem na carreira docente. E também, não é correto considerar a prática educacional como uma transferência de conhecimento, mas como uma ação que possibilita os meios para a construção desse conhecimento, Freire (2015) assim considera esta questão:

\footnotetext{
É preciso que, pelo contrário, desde os começos do processo vá ficando cada vez mais claro que, embora diferentes entre si, quem forma se forma e re-forma ao formar e quem é formado forma-se e forma ao ser formado. É neste sentido que ensinar não é transferir conhecimentos, conteúdos, nem formar é ação pela qual um sujeito criador dá forma, estilo ou alma a um corpo indeciso e acomodado. (FREIRE, 2015. p.25)
}

A ideia de que o ser humano está sempre apto a aprender no decorrer da vida, é primordial e essencial na carreira docente. $\mathrm{O}$ educador deve considerar o que o educando também tem a lhe oferecer de aprendizado, denotando um caráter de aprendiz constante sempre disposto a aprimorar seus conhecimentos, como também, se autoavaliar e refletir sobre suas práticas educativas.

O docente deve exigir do discente aquilo que ele é exemplo, sendo que um dos fatores mais agravantes que ocorre na educação pública brasileira é a pouca leitura de muitos professores. Este comportamento reflete de forma negativa em muitas situações da profissão, evidenciadas na formação, prática em sala de aula e na própria construção de identidade.

A leitura é uma iminência na formação docente, como forma de aquisição de conhecimento e desenvolvimento de habilidades educativas, além de ser uma forte aliada no processo da formação continuada. A célebre frase de Airton Ortiz "Nós somos resultado dos livros que lemos, das viagens que fazemos e das pessoas que amamos...”, faz menção a essência da leitura na vida do ser humano, principalmente na área educacional. Portanto, torna-se impossível promover qualidade profissional docente sem que a leitura seja um hábito.

E esse hábito é refletido não só no cotidiano escolar, mas na construção do professor como pessoa, onde Vasconcelos (2003) assim retrata essa questão:

Na memória do leitor reside não só o que ele leu, mas também o que significaram estas experiências de leitura ao longo da vida. Isto sinaliza como as experiências estão marcadas, hoje, na pratica de educador e de que forma a leitura se apresenta como 
uma prática cultural e social vinculada a outras tantas. (VASCONCELOS, 2003. p.100)

Neste sentido, não havendo uma rotina de leitura do professor, fica ainda mais difícil adquirir uma visão adequada da realidade a qual está inserido no âmbito escolar, além de dificultar a apropriação de autonomia profissional que consequentemente prejudicará sua identidade no decorrer de sua carreira do magistério.

Outro obstáculo que dificulta a construção das particularidades e qualidades docentes é o distanciamento que há entre a escola e a sociedade, não há uma ligação exata entre o que se aprende e o que se é evidenciado socialmente. Além do mais a educação tem sido apresentada como a solução de todos os problemas, as instituições de ensino estão desenvolvendo papéis mais de assistencialismo do que mesmo de construção de conhecimento, onde o aluno deixa de aprender a aprender, para apenas reproduzir o que é determinado ao meio escolar.

Neste contexto, a fragmentação do ensino também tem dificultado o trabalho do professor, no sentido deste pouco obter uma visão sistêmica da produção do conhecimento. Mosé (2015) assim se expressa a cerca desta problemática:

Creio que antes de discutir o currículo mínimo e se pensar em implantar mais disciplinas, ou se substituir conteúdo A pelo conteúdo B, a discussão deve prevalecer sobre como trabalhar o currículo, como fazer dos conteúdos a ferramenta para desenvolver. (MOSÉ, 2015. p. 191)

É neste âmbito que a construção identitária do professor tem sido de certa forma monitorada pelo discurso oficial, que condiciona as práticas educacionais aos interesses elitistas e seletistas, uma vez que, se torna bastante interessante a permanência da formação de cidadãos desprovidos do senso crítico em sociedade.

\section{Considerações Finais}

A situação educacional brasileira e o poder de decisão em relação a autonomia do professor, tem revelado muitos obstáculos que dificultam ou até mesmo impedem esse profissional de edificar sua identidade no campo educacional e até mesmo pessoal. 
A chamada crise do ensino tem demonstrado o quanto este ofício tem deixado de ser interessante e almejado na sociedade e, o que se é deliberado em termos de políticas públicas educacionais pouco está condizendo com a realidade e a necessidade das instituições de ensino contemporâneas.

A ação educacional está atrelada a uma série de fatores oriundos das dificuldades de interação social, desvalorização do profissional da educação, falta de condições dignas de trabalho, formação inicial e continuada precária e muitos outros problemas que não enobrece a imagem do professor.

Estes entraves têm prejudicado muitos docentes quanto às expectativas do ser professor, bem como a relevância do seu trabalho para a sociedade e para si próprio.

\section{Referências}

CAMPOS, Casemiro de Medeiros. Saberes docentes e autonomia dos professores. $3^{\mathrm{a}}$ ed. Petrópoles - RJ: Vozes, 2011.

FREIRE, Paulo. Pedagogia da Autonomia: saberes necessários a prática educativa. 51 ed. Rio de Janeiro: Paz e Terra, 2015.

MESSIAS, Cinthia Maria de Fontoura. Reflexões sobre a Formação Docente. Disponível em: www.ensino.eb.br/portaledu/conteudo/artigo9813.pdf. Acesso em 17/03/2016.

NEVES, Maria Apparecida C. Mamede. A crise dos paradigmas em educação na óptica da Psicologia. In: BRANDÃO, Zaia (org.) A crise dos paradigmas e a educação. $11^{\text {a }}$ ed. São Paulo: Cortez, 2010. Capítulo 3, p. 51-60.

PERRENOUD, Philippe. Dez Novas Competências para Ensinar. Trad. Patricia Chittoni Ramos. Porto Alegre: Artmed, 2000. 192 p.

RISTOFF, Dilvo. A Tríplice Crise da Formação do Professor. Grupo Estratégico de Análise da Educação Superior no Brasil - GEA. Disponível em: www.alainet.org/images/GEA_OPINIAO_N4.pdf. Acesso em: 17/03/2016.

TARDIF, Maurice. LESSARD, Claude. Oficio de professor - histórias, perspectivas e desafios internacionais. Petrópoles, RJ:Vozes, 2008. 
Id on Line Revista Multidisciplinar e de Psicologia

Id on Line Multidisciplinary and Psycology Journal

VASCONCELOS, Geni A. Nader (org.) Como me fiz professora. $2^{\mathrm{a}}$ ed. Rio de Janeiro: DP\&A, 2003.

\section{Como citar este artigo (Formato ABNT):}

OLIVEIRA, Antona K. A Construção da Identidade Docente numa Prática Educacional Complexa. Id on Line Revista Multidisciplinar e de Psicologia, Fevereiro de 2017, vol.11, n.34, p.362-371. ISSN: 1981-1179.

Recebido: 25.9.2016

Aceito:24.10.2016 